\title{
INHALTSÜBERSICHT
}

Vorwort .. . . . . . . . . . . . . . . . . 7

Einleitung Nr. 1-4 . . . . . . . . . . . . . . . . . . . . . . . 9

Erster Hauptteil

Die Mundarten der Kreise Oberbarnim und Teltow

Die Mundart von Heckelberg Nr. 5-47 . . . . . . . . . . . . . 13

Vokale - Konsonanten

Die Mundart des Kreises Oberbarnim Nr. 48-53 . . . . . . . . . 22

Vergleichende Darstellung der Sprache des Oberbarnim und des Teltow Nr. 54-73 . . . . . . . . . . . . . . . . . . . . . .

Vokale - Konsonanten - Wortbildung - Satzformen - Wortschatz

Zweiter Hauptteil

Das Sprachgefälle vom Westen zum Osten

Vokale Nr. 74-93 . . . . . . . . . . . . . . . . . . . . . .

Langdiphthonge - Langvokale - Hiatdiphthonge - Hebung vor $\mathbf{r}-$

Senkung vor $r$ - konsonantischer Umlaut - dät - dröschen - over / över - westgerm. ai > ie - siehen - Senkung des i zu e, des u zu o- $\mathrm{He}$ bung des e z u i-Ruëst - ndl. -oe i > - $\bar{u}-u-$, o-Umlaut - leiser Einsatz Entfaltung - Endungs-e

Konsonanten Nr. 94-103 . . . . . . . . . . . . . . . . . . .

Anlautendes g- $>$ spirantisch j- - Heininge - legen, sagen, liegen, Roggen - ft > cht - -nd- > -ng. - Dunder, Mölder - Umstellung Abfall und Antritt von -t - -el > -er - -en > -em

Wortbeugung und -bildung Nr. 104-111 . . . . . . . . . . . . jan- und jōn-Deklination - feminines Geschlecht - tu, geh, steh gekürzter Vokal und Umlaut in Verbformen - Umlautlosigkeit im Sing. Präs. - -ster - -sel - Diminutive auf -el, -sken, -kes

Satzlehre Nr. 112-113

Bredereiche - up 't Feld 
Ein älteres Zeugnis der teltowschen Mundart Nr. 114-116 $\quad . \quad$. . . 87

Niederländische Siedelwörter (Nachtrag) Nr. 117-125 . . . . . . . 91

\section{Dritter Hauptteil}

Mitteldeutsche Sprachzüge

Vokale Nr. 126-136 . . . . . . . . . . . . . . . . . . . . .

Langdiphthonge - Hiatdiphthonge - Hebung vor $\mathrm{r}-$ Käse, Schäfer, 102 gehn, Wetter, Trespe - droschen - Entrundung - Rundung - Umlaut / Umlautlosigkeit - reine / reene - Kürze / Länge - viel

Konsonanten Nr. 137-140 . . . . . . . . . . . . . . . . . . 110

Anlautendes wr- - -chs- > -ss- - p-/b- - änger, üngene

Wortbeugung und -bildung Nr. 141-148 . . . . . . . . . . . . 113

er - duch/tuk - ißt, gib, sei - (ich) habe, (sie) haben - gebrannt, erzählt - -e - Geresse - -ke

Wortschatz Nr. 149

Wiese

Die nd.-md. Grenzzone Nr. 150-156 . . . . . . . . . . . . . .

Breite der Grenzzone - Sprachgrenzen südlich der nd.-md. Hauptscheide - Lautverschiebungsgrenze - verschobene und unverschobene Konsonanten in einem Dorf - vokalische Grenzlinien - Sprach. geschichte des Klosters Dobrilugk - Diagonale Elbknie-Berlin

\section{Vierter Hauptteil}

Das ostfälische Altland und sein Verhältnis zur Mundart der Mark Brandenburg

Elbostfälisch Nr. 157-164 . . . . . . . . . . . . . . . . . . .

Die Elbe als Sprachgrenze - der Anteil Ostfalens am märkischen Siedelwerk - die Frühgeschichte Elbostfalens - nordsee- und nordgermanische Sprachzüge in Elbostfalen - küstenniederländische Gleichungen - märk. g. $>$ j- und g $>3-$ Niederländisch und Elbostfälisch

Die ostfälische Klammer Nr. 165-167

Das Siedelwerk an der Mittelelbe - linkselbische Sprachzeugnisse auf dem rechten Ufer - Elbostfälisches und Niederländisches, auch Mitteldeutsches in der Siedelsprache - die Mittelelbe als scharfe Sprachgrenze - Niederländisches in der Altmark - Mundart auf beiden Ufern Mitteldeutscher Einbruch längs der Elbe Nr. 171-172 
Fünfter Hauptteil

Slawisches in der deutschen Mundart Nr. 173-180 . . . . . . . . . . 144

Aufgabe und Methode - Vokale - Konsonanten - das anlautende h- deutsche und slawische Zischlaute - ostmd. f- statt pf- - das slawische gutturale 1 - Flexion - Wortbildung

\section{Sechster Hauptteil}

Landeskunde

Geschichte Nr. 181-195 .

Frühgeschichte - die Erwerbung der Mark - der Boden - die Siedlung der Slawen - Fortdauer slawischen Volkstums - die deutsche Besitznahme und Siedlung - rückgängige Siedlung - die zerrüttete Mundart - ihre Wiedergeburt - Prinzipielles

Die Karten

Lautschrift

Abkürzungen . . . . . . . . . . . . . . . . . . . . . . 173

Literaturverzeichnis . . . . . . . . . . . . 175

Wörterverzeichnis . . . . . . . . . . . . . . . . . 183 
